\title{
THE INFLUENCE OF PROMOTIONS ON DECISIONS SITINJAK VILLAGE COMMUNITY USING SAVING PRODUCTS HAJJ IN SHARIA BANK
}

\author{
Annisa Yuliana ${ }^{1}$, Fatahuddin A. Siregar ${ }^{2}$, Adanan Murroh $^{3}$, Veri Pramudia ${ }^{4}$ \\ ${ }^{1}$ IAIN Padangsidimpuan (Perbankan Syariah, FEBI, IAIN Padangsidimpuan) \\ ${ }^{2}$ IAIN Padangsidimpuan (Perbankan Syariah, FEBI, IAIN Padangsidimpuan) \\ ${ }^{3}$ IAIN Padangsidimpuan (Manajemen Zakat dan Wakaf, FEBI, IAIN Padangsidimpuan) \\ ${ }^{4}$ IAIN Padangsidimpuan (Ekonomi Syariah, FEBI, IAIN Padangsidimpuan) \\ annisayuliana@gmail.com ${ }^{1}$, fatahuddinaziz@iain-padangsidimpuan.ac.id ${ }^{2}$, adananmurroh@iain- \\ padangsidimpuan.ac.id ${ }^{3}$, veripramudia@iain-padangsidimpuan.ac.id ${ }^{4}$
}

\begin{abstract}
ABSTRAK
Tanpa promosi jangan diharapkan nasabah dapat mengenal bank, oleh karena itu, promosi merupakan sarana yang paling ampuh untuk menarik dan mempertahankan nasabahnya. Salah satu tujuan promosi bank adalah menginformasikan segala jenis produk yang ditawarkan dan berusaha menarik calon nasabah yang baru. Promosi bukan hanya alat komunikasi antar perusahaan dengan nasabah, melainkan juga sebagai alat untuk memengaruhi nasabah. Keputusan nasabah adalah pilihan alternatif keputusan yang dilakukan nasabah untuk menggunakan produk yang ditawarkan perusahaan. Penelitian ini merupakan penelitian kuantitatif dengan mengunakan analasisi regresi sederhana. Teknik pengumpulan yang digunakan oleh peneliti dalam penelitian ini adalah menggunakan angket serta melalui observasi terhadap individu yang informasinya diperlukan dalam penelitian ini. Angket merupakan teknik pengumpulan data yang dilakukan dengan cara memberi seperangkat pernyataan atau pertanyaan tertulis kepada responden untuk dijawab. Sampel yang digunakan dalam penelitian ini sebanyak 34 responden. Pengolahaan data dilakukan dengan SPSS versi 22. Hasil uji koefisien determinasi (R2) dapat diketahui bahwa Nilai $R$ Square sebesar 0,443 artinya variabel promosi mampu menjelaskan variabel keputusan menjadi nasabah sebesar 44,3 persen sedangkan 55,7 persen sisanya dijelaskan oleh variabel lain yang tidak dimasukkan dalam model ini. Dalam arti lain bahwa masih ada variabel yang memengaruhi keputusan menjadi nasabah selain promosi. Berdasarkan hasil penelitian ini menunjukkan pengaruh yang signifikan yaitu promosi terhadap keputusan dengan nilai $t_{\text {tabel }}<$ $t_{\text {hitung }}(2,036<5,041)$.
\end{abstract}

Kata Kunci: Promosi, Keputusan Nasabah

\begin{abstract}
Without promotion, it is not expected that customers can get to know the bank, therefore, promotion is the most effective means of attracting and retaining customers. One of the objectives of bank promotion is to inform all types of products offered and try to attract new prospective customers. Promotion is not only a communication tool between companies and customers, but also as a tool to influence customers. Customer decisions are alternative choices of decisions made by customers to use the products offered by the company. This research is a quantitative study using simple regression analysis. The collection technique used by researchers in this study is to use a questionnaire and through observation of individuals whose information is needed in this study. Questionnaire is a data collection
\end{abstract}


POINT Vol. 1, No. 1, Jul 2020

technique that is done by giving a set of statements or written questions to respondents to be answered. The sample used in this study were 34 respondents. Data processing is done with SPSS version 22. The results of the coefficient of determination (R2) can be seen that the $R$ Square value of 0.443 means that the promotion variable is able to explain the decision variable to be a customer by 44.3 percent while the remaining 55.7 percent is explained by other variables not included in this model. In another sense that there are still variables that influence the decision to become a customer in addition to promotion. Based on the results of this study indicate a significant influence that is the promotion of decisions with a $t_{\text {table }}$ $<t_{\text {count }}(2.036<5.041)$.

Keywords: Promotion, Customer Decision

\section{A. PENDAHULUAN}

Bank Islam memiliki istilah lain yaitu Bank Syariah. Secara akademik Islam dan Syari'ah memang mempunyai pengertian yang berbeda. Namun secara teknis untuk penyebutan Bank Islam dan Bank Syari'ah mempunyai pengertian yang sama.

Menurut ensiklopedia Islam, Bank Islam adalah lembaga keuangan yang usaha pokoknya memberikan kredit dan jasa-jasa dalam lalu lintas pembayaran serta peredaran uang yang pengoperasiannya disesuaikan dengan prinsipprinsip syariat Islam. (Warkum Sumirno,1996:5)

Bank Islam berarti bank yang tata cara beroperasinya didasarkan pada tata cara bermu'amalat secara Islam, yakni mengacu kepada ketentuan-ketentuan Al-Qur'an dan Hadis. Sedangkan pengertian muamalat adalah ketentuan-ketentuan yang mengatur hubungan manusia dengan manusia, baik hubungan pribadi maupun antara perorangan, dengan masyarakat. Mu'amalah ini meliputi bidang kegiatan jual-beli (ba'i), bunga (riba) piutang (qoroah), gadai (rohan), memindahkan utang (hawalah), bagi untung dalam perdagangan (Qiro'ah), jaminan (dhomah), persekutuan (syirkah), persewaan (ijarah).

Di dalam operasionalisasinya bank Islam harus mengikuti dan atau berpedoman kepada praktek-praktek usaha yang dilakukan di zaman Rasulullah, bentuk-bentuk usaha yang telah ada sebelumnya tetapi tidak dilarang oleh Rasulullah atau bentuk-bentuk usaha baru sebagai hasil ijtihad para ulama / cendikiawan muslim yang tidak menyimpang dari ketentuan Al-Qur'an dan Hadis. (Warkum Sumirno, 1996:6)

Perbedaan yang mencolok antara Bank Syariah dengan Bank Konvensional diantaranya, akad dan aspek legalitas, Bank Syariah menggunakan akad syariah, hukum Islam dan hukum positif sedangkan Bank Konvensional menggunakan akad konvensional, hukum positif. Struktur organisasi, Bank Syariah penghimpunan dan penyaluran dana harus sesuai dengan fatwa Dewan Syariah Nasional (DSN), Dewan Pengawas Syariah (DPS), sedangkan dengan Bank Konvensional tidak 
terdapat dewan sejenis DSN dan DPS, Bank Konvensional menggunakan dewan komisaris. Bisnis dan usaha yang dibiayai, Bank Syariah melakukan investasi-investasi yang halal saja, hubungan dengan nasabah dalam bentuk hubungan kemitraan, berdasarkan prinsip bagi hasil, jual beli atau sewa, berorientasi pada keuntungan (profit oriented) dan kemakmuran dan kebahagiaan dunia akhirat, sedangkan dengan Bank Konvensional melakukan investasi yang halal dan haram profit oriented, hubungan dengan nasabah dalam bentuk hubungan kreditur-debitur, memakai perangkat bunga. Lingkungan kerja, Bank Syariah dengan lingkungan yang Islam, sedangkan Bank Konvensional dengan lingkungan yang non Islam. (Amir Machmud \& H. Rukmana,2010:12)

Dalam perbankan syariah mereka memiliki kegiatan seperti penghimpunan (pendanaan), penyaluran (pembiayaan) dan jasa. Pertama yaitu penghimpunan dana, penghimpunan dana memiliki prinsip yaitu wadi'ah (titipan), qardh (pinjaman), mudharabah (bagihasil) dan ljarah (sewa), dan adapun produk perbankan dari penghimpunan dana diantaranya, giro dengan prinsip wadi'ah atau qardh, tabungan dengan prinsip wadi'ah, qardh atau mudharabah, deposito dengan prinsip mudharabah, dan obligasi atau saham dengan prinsip mudharabah, ijarah, dan lainlain. (Muhammad Syafii Antoni, 2001:169-174)

Kedua, yaitu penyaluran dana (pembiayaan), produk-produk penyaluran dana terbagi atas tiga bagian yaitu, pembiayaan modal kerja, pembiayaan investasi dan pembiayaan konsumtif. Pembiayaan modal kerja, yaitu modal kerja syariah dengan prinsip mudharabah, musyarakah, murabahah, salam. Pembiayaan Investasi yaitu pembiayaan investasi syariah dengan prinsip mudharabah, musyarakah, murabahah, istisna', ijarah, IMBT. Pembiayaan konsumtif yaitu Pengadaan barang investasi, aneka barang dengan prinsip murabahah, IMBT, musyarakah mutanaqisah. Perumahan, property dengan prinsip murabahah, IMBT, musyarakah mutanaqisah. Proyek dengan prinsip mudharabah musyarakah. Ekspor dengan prinsip mudharabah, musyarakah, murabahah. Produksi agribisnis/ sejenis dengan prinsip salam, salam paralel. Manu faktur, kontruksi dengan prinsip istisna'paralel. Penyertaan dengan prinsip musyarakah. Surat berharga dengan prinsip mudharabah, qardh. Sewa beli dengan prinsip IMBT. Akuisisi asset dengan prinsip IMBT. (Adiwarman A. Karim, 2004:231244)

Ketiga jasa perbankan, produk- produk jasa perbankan dibagi empat jasa yaitu jasa nonkeuangan, jasa keagenan, kegiatan sosial dan jasa keuangan. Jasa nonkeuangan yaitu safe defosito box dengan prinsip wakalah yaddamanah / ujr. Jasa keagenan yaitu investasi terikat (channeling) dengan prinsip mudharabah muqayyadah. Jasa social yaitu pinjaman social dengan prinsip qardhulhasan. Dan yang terakhir jasa keuangan diantaranya dana talangan dengan prinip qardh, anjak 
Annisa Yuliana ${ }^{1}$, Fatahuddin A. Siregar ${ }^{2}$, Adanan Murroh ${ }^{3}$, Veri Pramudia ${ }^{4}$

piutang dengan prinsip hiwalah, jual beli valuta asing dengan prinsip sharf, gadai dengan prinsip rahn, payroll dengan prinsip ujr / wakalah, bank garansi dengan prinsip kafalah, L/C, transfer, inkaso, klirik, RTGS, digital banking, dan sebagainya dengan prinsip wakalah.

Tabungan Haji sebenarnya mirip dengan tabungan berjangka syariah. Tabungan Haji sangat direkomendasikan bagi nasabah yang berencana untuk melaksanakan ibadah Haji ke Tanah Suci. Tabungan Haji adalah jenis produk tabungan syariah berdasarkan akad wadiah dan mudharabah mutlaqah yang sesuai dengan prinsip Islam. Nasabah menyetorkan jumlah dana dengan jumlah tetap dalam jangka waktu tertentu hingga target dana tercapai. Dana yang terkumpul akan digunakan sebagai pembiayaan pelaksanaan ibadah Haji nasabah. (Ascarya, 2007:129)

Tabungan Haji wadiah dijalankan berdasarkan akad wadiah, yaitu titipan murni harus dijaga dan dikembalikan setiap saat sesuai dengan kehendak pemiliknya. Tabungan Haji mudharabah mutlaqah adalah dijalankan berdasarkan akad mudharabah mutlaqah. Nasabah tidak memberikan pembatasan bagi bank syariah dalam menggunakan dana yang disimpannya. Bank Syariah bebas untuk menetapkan akad seperti apa yang dipakai ketika menyalurkan pembiayaan, kepada siapa pembiayaan itu diberikan, dan usaha seperti apa yang dibiayai. Sehingga prinsip mudharabah mutlaqah lebih memberikan keluasan bagi bank.
POINT Vol. 1, No. 1, Jul 2020

Manajemen pemasaran, pemasaran berhubungan dengan mengidentifikasi dan memiliki kebutuhan manusia dan masyarakat. Salah satu definisi pemasaran terpendek adalah memenuhi kebutuhan secara menguntungkan, jadi manejemen pemasaran sebagai seni dan ilmu memilih pasar sasaran dan mendapatkan, menjaga, dan membutuhkan pelanggan dengan menciptakan, menyerahkan dan mengomunikasikan nilai pelanggan yang unggul.

Promosi merupakan kegiatan marketing mix yang terakhir. Kegiatan ini merupakan kegiatan yang sama pentingnya dengan ketiga kegiatan diatas, baik produk, harga dan lokasi. Dalam kegiatan ini setiap bank berusaha untuk mempromosikan seluruh produk dan jasa yang dimilikinya baik langsung maupun tidak langsung. (Philip Kotler \& Kevin Lane Keller, 2007:6)

Tanpa promosi jangan diharapkan nasabah dapat mengenal bank, oleh karena itu, promosi merupakan sarana yang paling ampuh untuk menarik dan mempertahankan nasabahnya. Salah satu tujuan promosi bank adalah menginformasikan segala jenis produk yang ditawarkan dan berusaha menarik calon nasabah yang baru. Kemudian promosi juga berfungsi mengingatkan nasabah akan produk, promosi juga ikut memengaruhi nasabah untuk membeli dan akhirnya promosi juga akan meningkatkan citra bank di mata para nasabahnya. 
Kelurahan Sitinjak adalah salah satu kelurahan di Kecamatan Angkola Barat, Kabupaten Tapanuli Selatan yang memiliki luas $1.870 \mathrm{~km}$. Memiliki jumlah penduduk sebanyak 4.512 jiwa, jumlah Kepala Keluarga (KK) sebanyak 1.385, jumlah laki-laki sebanyak 2.289 dan jumlah perempuan sebanyak 2.223 dan yang telah menunaikan Ibadah Haji sebanyak 49 orang, mayoritas beragama Islam. Dan yang beragama non muslim sebanyak 2 keluarga. Peneliti berkesempatan mewawancarai bapak Lurah dan beliau mengatakan "bahwa Bank Syariah belum pernah mengadakan promosi tentang produk Tabungan Haji di Kelurahan Sitinjak".

Peneliti juga melakukan mewawancarai dengan beberapa orang masyarakat Kelurahan Sitinjak, Kecamatan Angkola Barat, Kabupaten Tapanuli Selatan yaitu: Ibu $\mathrm{Hj}$. Tettiy Dalimunthe mengatakan: alasannya tidak menggunakan Bank Syariah dan menggunakan Bank Konvensional sebagai Bank untuk mendaftar sebagai calon Jamaah Haji yaitu karena sebagai pegawai di daerah PEMKAB (Pemerintahan Kabupaten) Sudah dianjurkan untuk menabung di Bank SUMUT sebagai Bank Daerah, Bapak H. Parlaungan Hutasuhut juga mengatakan: alasannya tidak menggunakan Bank Syariah sebagai Bank untuk tempat mendaftar Haji karena mantan pegawai juga dianjurkan untuk menggunakan Bank daerah yaitu Bank SUMUT, Bapak H. Dalkot Batubara mengatakan: alasan menggunakan Bank Syariah sebagai bank untuk mendaftar Haji karena ketika manasik Haji tidak perlu ke Medan untuk melaksanakannya karena pelaksanaannya sudah bisa di Padangsidimpuan yaitu di Mesjid Raya tidak seperti Bank Konvensional harus ke Medan untuk melaksanakan manasik Haji tersebut.

Selain itu peneliti juga telah melakukan observasi ke beberapa Bank Syariah yang terjangkau dari Kelurahan Sitinjak yaitu Bank Syariah Mandiri, Bank Sumut Syariah dan Bank Muamalat di Kota Padangsidimpuan. Dari observasi yang peneliti lakukan bahwa dari ketiga bank tersebut memberikan pernyataan yang sama bahwa mereka belum pernah melakukan kegiatan promosi ke Kelurahan Sitinjak. Kegiatan promosi yang biasanya dilakukan yaitu promosi lewat radio, penyebaran brosur, dan pemasangan spanduk, dan kegiatan promosi ini juga dilakukan ketika menjelang Ramadhan saja, ketika hari- hari biasa promosi sudah tidak dilakukan bahkan brosur saja sudah tidak ada. Maksud dan tujuan penelitian ini adalah untuk mengetahui pengaruh promosi terhadap keputusan masyarakat Kelurahan Sitinjak menggunakan produk tabungan Haji.

\section{B. METODE}

Lokasi penelitian yang diteliti adalah masyarakat Kelurahan Sitinjak Kecamatan Angkola Barat Kabupaten Tapanuli Selatan. Sedangkan waktu penelitian mulai dari bulan Agustus Sampai Bulan Februari 2020

Jenis penelitian yang digunakan adalah penelitian kuantitatif, dimana menurut Creswell 
Annisa Yuliana ${ }^{1}$, Fatahuddin A. Siregar ${ }^{2}$, Adanan Murroh ${ }^{3}$, Veri Pramudia ${ }^{4}$

yang dikutip dari Asmadi Asla penelitian kuantitatif adalah "penelitian yang bekerja dengan angka, yang di analisis dengan menggunakan statistik untuk menjawab pertanyaan atau hipotesis penelitian yang sifatnya spesifik". (Asmadi Alsa,2004:13)

Berdasarkan permasalah yang telah dikemukakan harus dikumpulkan data yang relevan. Sumber data yang dikumpulkan dan yang diperlukan dalam penelitian ini adalah, Data Primer, menurut Sugiyono, "data primer adalah sumber data yang langsung memberikan data kepada pengumpul data". Data primer dalam penelitian ini adalah data yang diperoleh secara langsung dari hasil kuesioner pihak yang bersangkutan. (Sugiyono,2016:116)

Teknik pengumpulan data yang dilakukan dalam penelitian ini adalah:

a. Observasi

Menurut Muhammad Teguh, dia menyatakan bahwa: Teknik pengumpulan data yang dilakukan melalui suatu pengamatan, dan disertai pencatatanpencatatan terhadap keadaan atau pelaku objek sasaran. Orang yang melakukan observasi disebut pengobservasi dan pihak yang diobservasi disebut terobservasi. (Abdurrahmat Fathoni,2011:104).

b. Angket atau kuesioner

Angket digunakan untuk mengukur bagaimana tingkat Pengaruh Promosi Terhadap Keputusan Masyarakat Kelurahan Sitinjak Menggunakan Produk Tabungan Haji Di Bank Syariah. Dalam hal ini menggunakan skala ordinal. Skala ordinal Adalah skala pengukuran yang sudah dapat
POINT Vol. 1, No. 1, Jul 2020 digunakan untuk menyatakan peringkat antar tingkatan, akan tetapi jarak atau interval antar tingkatan belum jelas. Metode yang digunakan dalam penggunaan koesioner dengan skala likert.

Skala likert digunakan untuk mengukur sikap, pendapat, dan sosial. Dalam penelitian, fenomena sosial ini telah ditetapkan secara spesifik oleh peneliti, yang selanjutnya disebut dengan variabel penelitian. Dengan skala likert, maka variabel yang akan diukur dijabarkan menjadi indikator variabel. Kemudian indikator tersebut dijadikan sebagai titik tolak untuk menyusun item-item instrumen yang dapat berupa pertanyaan.

\section{HASIL DAN PEMBAHASAN}

Penelitian berjudul pengaruh keputusan masyarakat kelurahan Sitinjak menggunakan produk tabungan Haji di Bank Syariah, diolah menggunakan SPSS vers 22 . Berdasarkan hasil regresi yang dilakukan pada penelitian ini diperoleh persamaan regresi yaitu:

1. Dapat dilihat dari hasil analisis regresi sederhana diperolah persamaan $\mathrm{Y}=\mathrm{a}+\mathrm{bX}$ (Keputusan Nasabah $=8,329+0,692$ Promosi), dengan demikian diketahui bahwa parameter koefisien regresi untuk variabel promosi adalah positif terhadap keputusan nasabah, artinya setiap terjadi peningkatan variabel promosi pada nasabah, maka keputusan nasabah juga akan mengalami peningkatan. 
2. Dari hasil analisis dan pengujian hipotesis yang telah dilakukan, maka diperoleh hasil yang menunjukkan bahwa hipotesis alternatif yang menyatakan bahwa ada pengaruh antara promosi terhadap keputusan nasabah dapat diterima. Hal ini dibuktikan berdasarkan perhitungan uji $\mathrm{t}$ dengan hasil uji $t=5,041$. Hasil analisis data menunjukkan bahwa $\mathrm{t}$ hitung $>\mathrm{t}$ tabel $(5,041>2,036)$, maka hipotesis alternatif diterima dan dan variabel promosi menunjukkan nilai taraf signifikan $0,00<$ 0,05 yang berarti signifikan.

Dalam upaya mendefenisikan seberapa jauh pengaruh variabel promosi terhadap keputusan nasabah, perlu dilihat dari nilai koefisien determinasinya. Berdasarkan perolehan koefisien determinasi sebesar 0,443 menunjukkan bahwa besarnya variabel promosi dapat dijelaskan oleh variabel promosi sebesar 44,3 persen sedangkan 55,7 , dijelaskan oleh faktor- faktor lain diluar penelitian ini yang tidak dimasukkan dalam model ini. Dalam arti lain bahwa masih ada variabel yang memengaruhi keputusan menjadi nasabah selain promosi.

Promosi merupakan kegiatan yang aktif dilakukan oleh perusahaan untuk mendorong nasabah melakukan transaksi dalam bentuk apapun. Promosi merupakan variabel dari bauran pemasaran. Bauran promosi sabagai salah satu variabel dalam pemasaran yang bertujuan untuk mencapai tujuan dan sasaran perusahaan, melalui promosi maka Bank
Syariah memperoleh nasabah. Sehingga, makin banyak kegiatan promosi yang dilakukan Bank Syariah.

Hasil penelitian ini terbukti bahwa promosi berpengaruh signifikan terhadap keputusan nasabah, memberikan pengertian bahwa semakin tinggi dan menariknya promosi yang dilakukan oleh perusahaan, maka akan semakin tinggi pula keputusan konsumen dalam melakukan pembelian dan berlangganan pada produk/ jasa tersebut.

Hasil penelitian terdahulu dari skripsi Neneng Fajriyah dalam penelitiannya menyatakan bahwa "promosi berpengaruh terhadap keputusan nasabah dalam menggunakan tabungan haji." Sama halnya dengan penelitian yang dilakukan oleh Arun Wahidmaheni yang menyatakan bahwa promosi memberikan pengaruh positif dan signifikan terhadap keputusan nasabah pada bank syariah.

\section{PENUTUP}

\section{Kesimpulan}

Bersadarkan pada hasil analisis data dan pembahasan mengenai pengaruh promosi terhadap nasabah dengan metode analisis yang digunakan yaitu regresi sederhana, maka dapat ditarik kesimpulan bahwa hasil regresi penelitian ini menunjukkan adanya pengaruh yang posistif dan signifikan antara variabel promosi $(\mathrm{X})$ terhadap keputusan nasabah $(\mathrm{Y})$ yang terlihat dari regresi $Y=8,329+0,692 \mathrm{X}$. Hal ini menunjukkan bahwa peringkat promosi akan memengaruhi peningkatan keputusan nasabah. 
Dari hasil $t$ diperoleh $t_{\text {hitung }}>t_{\text {tabel }}(5,041>$ 2,036) dan tingkat signifikan yang diperoleh $0,00<\alpha(0,05)$ maka $\mathrm{HO}$ ditolak dan $\mathrm{Ha}$ diterima. Jadi dapat disimpulkan bahwa hasil pengujian persial koefisien promosi berpengaruh signifikan terhadap keputusan nasabah (masyarakat kelurahan Sitinjak) dalam menggunakan tabungan Haji di Bank Syariah.

\section{Saran}

Semoga adanya pengetahuan masyarakat terhadap minat produk perbankan syariah

\section{DAFTAR PUSTAKA}

Andi Prastowo, Memahami Metode-metode Penelitian: Suatu Tinjauan Teoritis dan Praktis Jogjakarta: Ar-Ruzz Media, 2014.

Adrianto, Manajemen Bank Syariah Implementasi Teori dan Praktek CV. Penerbit Qiara Media, 2019.

Abdul Rahman Saleh dan Muhbib Abdul Wahab, Psikologi Suatu Pengantar dalam Perspektif Islam Jakarta: Penada Media, 2004.

Amsal Bakhtiar, Filsafat Ilmu Jakarta: PT.Raja Grafindo Persada, 2010.
POINT Vol. 1, No. 1, Jul 2020

Arikunto S, Evaluasi Pendidikan Jakarta: Rineka Cipta, 1994.

Ahmad Tafsir, Filsafat Umum Akal dan Hati Sejak Thales Sampai Capra Bandung: PT Remaja Rosdakarya, 2003.

Choirul Mahfud, Pendidikan Multikultural Yogyakarta: Pustaka Pelajar, 2013.

Departemen Pendidikan Nasional, Kamus Besar Indonesia Jakarta: Balai Pustaka, 2005.

Dedy Mulyana, Metode Penelitian Kualitatif Yogyakarta: Pustaka Pelajar, 2006.

Ismail, Perbankan Syariah Jakarta: Prenadamedia Group, 2014.

Kasmir, Manajemen Perbankan Jakarta: Rajawali Pers, 2012.

Muhammad Uzer Usman, Menjadi Guru Profesional Bandung: PT. Remaja Rosdakarya, 2003 cet, ke-25.

Muhammad, Metodologi Penelitian Ekonomi Islam Jakarta: Raja Wali Press, 2009.

Mudrajad Kuncoro, Metode Riset Bisnis dan Ekonomi Jakarta: PT. Raja Grafindo Persada, 2010.

Mardalis, Metode Penelitian Suatu Pendekatan Proposal Jakarta: Bumi Aksara, 2007. 